\section{Enfermedad por coronavirus 2019 (COVID-19) y su repercusión en la consulta odontológica: una revisión}

\section{Coronavirus disease 2019 (COVID -19) and its impact on dental practice: a review}

\begin{abstract}
Resumen
La presencia de la nueva pandemia COVID-19 o SARS-CoV-2 evidencia la necesidad de adoptar medidas que minimicen, prevengan y controlen el riesgo de infección y la propagación del virus en la práctica odontológica. Por lo cual, el objetivo de este artículo es establecer las repercusiones en los distintos ámbitos de la atención odontológica ante la presencia del virus, en relación con la práctica de control de infecciones dentales, las características de contagio de este (en los diferentes escenarios estomatológicos), los procedimientos odontológicos y las posibles consideraciones durante la pandemia. Concluyendo que en la práctica odontológica se debe priorizar los procedimientos de emergencia a aquellos pacientes sin síntomas respiratorios además de la evaluación previa para descartar cualquier sintomatología relacionada con el virus, precautelando la salud de profesionales y pacientes que interactúan durante la consulta odontológica.
\end{abstract}

Palabras clave: Coronavirus; Pandemias; Control de infecciones; Síndrome respiratorio agudo severo; Cuidado dental (fuente: DeCS BIREME).

\begin{abstract}
The presence of the new pandemic COVID-19 or SARS-CoV-2 shows the need to adopt measures that minimize, prevent, and control the risk of infection and the spread of the virus in dental practice. Therefore, the objective of this article is to establish the repercussions in different areas of dental care facing the presence of the virus, in relation to the practice of dental infection control, its contagion characteristics (in different stomatological scenarios), dental procedures and possible considerations during the pandemic. Concluding that in dental practice, emergency procedures should be prioritized to those patients without respiratory symptoms in addition to the prior evaluation to rule out any symptomatology related to the virus, protecting the health of professionals and patients who interact during the dental consultation.
\end{abstract}

Keywords: Coronavirus; Pandemics; Infection Control; Severe acute respiratory syndrome; Dental care (source: MeSH NLM).

\section{Artículo de Revisión}

Mariela Ramírez-Velásquez ${ }^{1, a}$, Priscilla Medina-Sotomayor ${ }^{1, b}$, Ángel Aurelio Morocho Macas ${ }^{1, c}$

1 Universidad Católica de Cuenca sede Azogues, Azogues, Ecuador.

a Doctora en Ciencias Odontológicas.

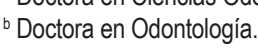

c Magíster en Administración de Tecnologías de Información.

\section{Correspondencia:}

Mariela Ramírez Velásquez: mramirezv@ucacue.edu.ec Universidad Católica de Cuenca, Av. 16 de abril y Ernesto Che Guevara, Azogues, Ecuador, 030102.

ORCID: 0000-0001-7041-4346

\section{Coautores:}

Priscilla Medina Sotomayor: ipemedinas@ucacue.edu.ec ORCID: 0000-0002-8117-8550

Ángel Aurelio Morocho Macas: amorocho@ucacue.edu.ec ORCID: 0000-0003-2946-1284

\section{Editor invitado:}

Donald Ramos-Perfecto

Universidad Nacional Mayor de San Marcos, Perú.

Conflicto de intereses: los autores declaran no tener conflictos de interés.

Fuente de financiamiento: autofinanciado.

Recibido: $16 / 04 / 20$

Aceptado: $20 / 04 / 20$

Publicado: 09/05/20

(C) Los autores. Este artículo es publicado por la revista Odontología Sanmarquina de la Facultad de Odontología, Universidad Nacional Mayor de San Marcos. Este es un artículo de acceso abierto, distribuido bajo los términos de la licencia Creative Commons Atribucion - No Comercia_Compartir Igual 4.0 Internacional. (http://creativecommons.org/licenses/by-nc-sa/4.0/) que permite el uso no comercial, distribución y reproducción en cualquier medio, siempre que la obra original sea debidamente citada. 


\section{Introducción}

En un periodo de corto tiempo, el brote de neumonía causada por un nuevo coronavirus llamado nueva neumonía por coronavirus (NNC) se presentó por primera vez en China, extendiéndose rápidamente a 24 países y regiones del mundo. El número de casos confirmados y muertes continúa aumentando. La Organización Mundial de la Salud (OMS) anunció que los brotes del nuevo coronavirus han constituido una emergencia de salud pública de preocupación internacional. El control eficaz de la infección puede evitar que el virus se propague aún más ${ }^{1}$.

Debido a la especialidad de los entornos de atención médica bucal, el riesgo de infección cruzada es grave entre los pacientes y los profesionales de la salud bucal, por lo cual es urgente implementar protocolos de control de infecciones estrictos y eficientes.

A continuación se comunica, una revisión de las pautas existentes y las investigaciones publicadas pertinentes a los principios y prácticas de control de infecciones dentales, discutiendo principalmente las características de la infección en los entornos de la atención estomatológica y recomendaciones sobre la evaluación de protocolos de control de infecciones en las circunstancias actuales.

\section{Revisión de la literatura}

\section{Antecedentes}

Desde el descubrimiento del nuevo coronavirus, en diciembre del 2019, la neumonía causada por él, conocida como NNC es altamente contagiosa y la población es generalmente susceptible. Recientemente este virus se denominó oficialmente coronavirus 2 del síndrome respiratorio agudo severo (SARS-CoV-2), el número de casos confirmados, sospechosos y fatales reportados por la OMS continúa aumentando y la situación de prevención y control de la epidemia es sombría.

El virus surgió en Wuhan, provincia de Hubei, China y se expandió rápidamente al resto del mundo, transmitido principalmente por inhalación o contacto con superficies contaminadas, cuenta con un período de incubación de 2 a 14 días con una media de 5 días ${ }^{2,3}$.

Los coronavirus son virus con genoma ARN, que poseen una envoltura lipoproteica, y cuyo diámetro varía de 60 a $140 \mathrm{~nm}$. En la superficie existen proyecciones en forma de espigas que al microscopio electrónico tienen la apariencia de corona. (Figura 1)

El virus ha sido identificado como un coronavirus que presenta similitud en un $95 \%$ con el coronavirus de murciélago y un $70 \%$ de similitud con el SARS-CoV ${ }^{2}$. Todas las personas sin distinción de edad son susceptibles de infección, debido a que las gotas que se generan durante el estornudo o la tos de pacientes asintomáticos llevan gran cantidad de carga viral ${ }^{4}$. Los pacientes pueden estar infectados durante todo el tiempo que los síntomas duren, incluso en el período de recuperación. Las gotas contaminadas pueden alcanzar 1-2 m y depositarse en las superficies durante un período de tiempo, siendo susceptibles a la desinfección con hipoclorito de sodio y peróxido de hidrógeno ${ }^{5}$.

En vista de la naturaleza especial de las operaciones de diagnóstico y tratamiento bucal, además del alto riesgo de infección cruzada se ha visto la necesidad de tomar medidas de protección correctas durante el diagnóstico y el tratamiento bucal para prevenir infecciones.

\section{Manifestaciones clínicas}

Las manifestaciones clínicas son variadas, desde un estado asintomático hasta el síndrome de dificultad respiratoria

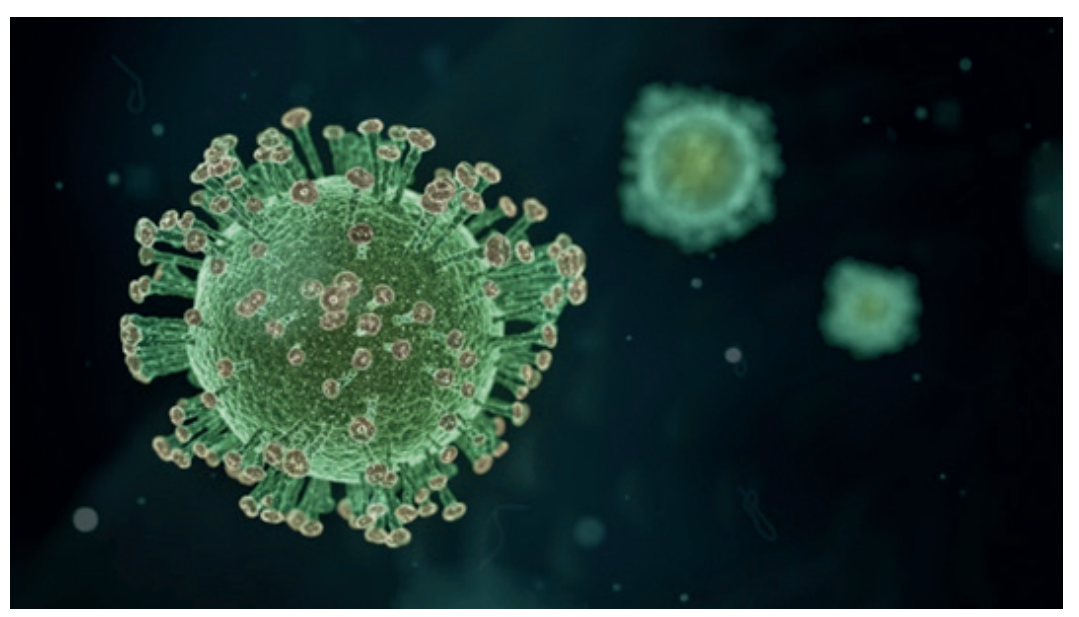

Figura 1. Partícula del coronavirus 2 del síndrome respiratorio agudo severo (SARS-CoV-2) bajo microscopio electrónico. Fuente: Tomado de Creative Commons (https://www.flickr.com/photos/ yusamoilov/49679288857/in/photolist-2iFZkM4-2iCBt7X-2iHUFdT-2iLYhir-2iHxBMr-2iFZcRv2iKxrbU-2iGhjYY-2iDnLMP-2iDRP1p-2iJveA5-2iGWUaM-2iGGzNJ-2iHatBh-2iG5Bik-2iDtnpd-2iE8cWF-2iHvsLH-2iDVEkh-2iKWEGv-2iL4ECe-2iLm4qR-2iG47oH-2iHA83R-2iLm4wN-2iHHPBU2iERn99-2iCtzbC-2iQCZ7h-2iGYJoM-2iHKtKP-2iGeCcS-2iBtQz8-2iJmxif-2iF8SQY-2iGLDHy-2iEcYjF-2iMVMei-2iRRYae-2iFFbzh-2ipTdX5-2iL78yp-2iPbvmk-2iRRYnZ-2iQXffo-2iAtWAh-2iKdmov2iFLoMn-2iRoLvN-2iJe3jK/) 
aguda y disfunción multiorgánica. Las características clínicas más comunes incluyen: fiebre (no en todos los pacientes), tos, dolor de garganta, fatiga, dolor de cabeza, mialgia y disnea. La conjuntivitis también se ha descrito como una manifestación clínica ${ }^{6}$. Se han reconocido cuatro tipos de coronavirus llamados HKU1, NL63, 229E y OC43, todos ellos circulando en humanos y generalmente causando enfermedad respiratoria leve ${ }^{2}$.

La característica común de la enfermedad es el progreso a neumonía al final de la primera semana, fallo respiratorio y muerte, esta progresión está asociada a un aumento extremo de las citosinas inflamatorias, incluidas IL-2, IL-7, IL-10, GCSF, IP10, MCP1, MIP1A y TNF- $\alpha^{6}$.

La media del tiempo de inicio de los síntomas hasta la disnea se describe de 5 días, la hospitalización de 7 días y el síndrome de dificultad respiratoria 8 días. La necesidad de ingreso en cuidados intensivos está en el 20-30\% de los pacientes infectados. Las complicaciones incluyen lesión pulmonar aguda, síndrome agudo respiratorio (SAR), shock y lesión renal aguda. La recuperación comienza en la segunda o tercera semana, la media de hospitalización de los pacientes recuperados es de 10 días. Los ancianos y aquellos con comorbilidades subyacentes (50-75\% de los casos fatales) son los más propensos a la muerte. La tasa de mortalidad en pacientes adultos hospitalizados oscila entre los $4-11 \%$. La severidad en los casos de neonatos, lactantes y niños son significativamente más suaves que en los adultos ${ }^{7}$. Sin embargo, en pacientes con enfermedades preexistentes como enfermedades cardiovasculares, hipertensión, enfermedades respiratorias, cáncer, obesidad, fumadores, se asocia el mayor riesgo de complicaciones y muerte ${ }^{8,9}$.

\section{Vías de transmisión}

Las principales vías de transmisión son directas y por contacto ${ }^{10}$ :

El virus del COVID-19 ha sido recientemente identificado en la saliva de paciente infectados, por la tanto la propagación a través de las gotas del tracto respiratorio cuando el paciente tose, estornuda o habla en voz alta son vías de transmisión durante la consulta odontológica ${ }^{11,12}$. El contacto personal cercano con una persona infectada es la razón por la que la OMS recomienda el aislamiento social.

Otra forma de contagio se produce al extenderse, en las manos, patógenos al contacto con superficies inanimadas ${ }^{13}$ y luego entrar en contacto con la cavidad bucal, nasal, ojos y otras membranas mucosas. Los patógenos en la sangre o los fluidos corporales con sangre también pueden ingresar al cuerpo humano a través de la mucosa o piel dañada por los aerosoles usados en los procesos odontológicos y causar infección ${ }^{1,3,10}$.

\section{Protocolos clínicos de atención odontológica}

El contacto cercano y frecuente con los pacientes en la consulta dental, expone al personal médico bucal a riesgo de exposición al nuevo coronavirus, debido a que el diagnóstico y tratamiento bucal tiene una particularidad, que durante el examen bucal el odontólogo y el paciente se encuentran cara a cara. El paciente tose o estornuda y el profesional corta tejidos duros de las piezas dentales o usa instrumentos ultrasónicos durante los tratamientos de la boca, lo que puede provocar que las secreciones, saliva o sangre del paciente salpiquen, y sin haber las medidas de protección adecuadas, las partículas grandes o pequeñas de gotas suspendidas en el aire, podrían llegar a la conjuntiva, mucosa bucal o nasal del profesional, causando infección. Además, también existe el riesgo de una infección cruzada entre los pacientes debido a los instrumentos odontológicos utilizados para los tratamientos dentales como la turbina, pudiendo quedar restos de microorganismos patógenos luego de su uso. Cuando las manos del personal odontológico o los pacientes entran en contacto con estos instrumentos contaminados, puede haber el riesgo de infección ${ }^{14}$.

Es necesario debido a las particularidades propias de las consultas odontológicas con un riesgo de infección cruzada alto entre odontólogos y pacientes, en países y/o regiones afectadas o en riesgo de COVID-19, ciertas consideraciones para el control y/o prevención del virus. Este artículo basado en investigaciones relevantes, presenta consideraciones esenciales sobre COVID-19 y la infección nosocomial en los consultorios odontológicos y proporciona recomendaciones para profesionales odontólogos y estudiantes en áreas (potencialmente) afectadas durante y después de superar la pandemia COVID-19.

\section{En la sala de espera}

Las clínicas odontológicas deben establecer una clasificación previa al examen para evaluar a los pacientes con fiebre. La oficina de preinspección o triaje debe mantener una buena ventilación y el personal debe estar equipado con instalaciones de monitoreo rápido de temperatura, desinfectantes de piel y equipo de protección personal. Si se encuentra un paciente con fiebre durante el triaje se le debe proveer inmediatamente una mascarilla e indicarle el hospital más cercano, solo se debe realizar el tratamiento bucal después de resolver los síntomas, incluso se ha informado que después de que un paciente con infección por SARS-CoV se cura, el diagnóstico y tratamiento bucal debe posponerse hasta un mes después del alta ${ }^{15}$.

\section{Protección del personal}

Durante el período de prevención y control de la epidemia, los odontólogos deben aprender activamente a controlar el coronavirus en la consulta diaria, con un buen manejo del paciente para prevenir infecciones cruzadas y con la correcta protección al personal durante el diagnóstico y tratamiento, así se previene la propagación de la epidemia y se garantiza la calidad odontológica y la seguridad del paciente.

Las medidas estrictas de higiene de manos son para prevenir cualquier fuente de infección ${ }^{14,15}$ además, en comparación con otros coronavirus, el COVID-19 sobrevive más 
tiempo in vitro ${ }^{1}$ reforzando la necesidad de una buena higiene de manos y la importancia de desinfectar completamente la superficie de los objetos. La higiene de manos se debe realizar antes de contactar con el paciente para una operación aséptica, después de contactar al paciente, después de la exposición a los fluidos corporales y después de contactar al entorno circundante del paciente, equipados con agentes de limpieza calificados, antisépticos de manos entre otras. La luz ultravioleta de $254 \mathrm{~nm}$ también ha sido descrita como un inactivador del coronavirus cuando se encuentra en suspensión, el proceso debe realizarse a puerta cerrada durante quince minutos ${ }^{16}$.

Es importante recordar que el uso de guantes no es un sustituto para lavarse las manos, y debe hacerse este procedimiento después de quitárselos ${ }^{1}$.

El equipo de protección del personal debe incluir guantes, gorras, mascarillas, gafas, máscaras protectoras, trajes de aislamiento y ropa protectora, diseñados para prevenir la piel, las membranas mucosas de los ojos, la boca, la nariz, etc. Además, el personal debe poder ponerse y quitarse el equipo de protección de manera correcta y hábil. La transmisión de gotas es una de las principales rutas de transmisión del nuevo coronavirus, por lo tanto, las mascarillas médicas pueden proporcionar una protección adecuada para el diagnóstico y tratamiento bucal diario. De acuerdo con la OMS, los pacientes que entran en contacto con el COVID-19, deben usar mascarillas $\mathrm{N} 95{ }^{17}$, ajustarse perfectamente a la cara y limitando su uso a cinco veces siguiendo las recomendaciones del fabricante ${ }^{18}$. Si el equipo de protección llegara a contaminarse durante el diagnóstico o tratamiento, debe remplazarse o desinfectarse de inmediato. Después del uso, las gafas protectoras deben limpiarse y desinfectarse con etanol al 75\% o colocarse en 500- 1000 $\mathrm{mg} / \mathrm{L}$ de desinfectante que contenga cloro durante 30 minutos, luego enjuagarse con agua corriente y secarse para su uso ${ }^{1}$.

\section{Atención del paciente}

Ante la situación epidemiológica de la enfermedad provocada por el nuevo coronavirus registrada en América y el mundo, quedó limitada la atención odontológica de emergencia a aquellas personas sin síntomas respiratorios.

El manejo temprano de las emergencias dentales agudas es importante para evitar que los pacientes por accidentes y emergencias culminen en ingresos hospitalarios y además preocupa que con la suspensión de la atención dental diaria o de rutina, más pacientes de lo habitual podrían necesitar admisión para el tratamiento de infecciones dentales agudas que amenazan las vías respiratorias y/o requieran cuidados intensivos. Los pacientes con graves inflamaciones pueden progresar a emergencias potencialmente mortales, lo que puede aumentar los riesgos en el contexto de la disminuida disponibilidad de atención médica. Para tales pacientes, las extracciones dentales deben priorizarse sobre un tratamiento restaurador. Debe considerarse además la administración de antimicrobianos, lo cual es una desviación de la odontología de rutina que debe discutirse a fondo con los pacientes. Las decisiones sobre la realización del tratamiento deben tomarse con el consentimiento apropiado del paciente ${ }^{19}$.

De igual manera será necesaria ante la aparición de este virus la reorganización oportuna de los servicios en la consulta odontológica diaria en cualquier consultorio público, o privado como una estrategia de control de infecciones para prevenir la propagación de la COVID-19. La figura 2 representa las divisiones en el área de atención de emergencia en la Escuela y Hospital de Estomatología, Universidad de Wuhan, durante el brote de la enfermedad por coronavirus 2019 donde las distintas áreas están separadas dependiendo del grado de probabilidad de contagio ${ }^{20}$.

Entre las recomendaciones según la experiencia vivida en dicho hospital, todo el personal de triaje que labore en el área amarilla debe usar mascarilla quirúrgica desechable, gorro y ropa de trabajo. En el área naranja, el personal odontológico debe contar con el equipo de protección personal, que incluye mascarilla desechable N95, guantes, batas, gorro, cubierta de zapatos y gafas o careta, además de ropa protectora. La clínica de aislamiento (área roja) destinada para pacientes con sospecha de COVID-19, quienes se están recuperando de COVID-19 (pero menos de un mes después de ser dados de alta), o para pacientes que necesitan procedimientos dentales que producen gotas y / o aerosoles. El área debe ser desinfectada una vez cada medio día. Además, toda el área de aislamiento se desinfecta inmediatamente después de que finaliza el tratamiento y el paciente se ha ido. El área de la cuadrícula detrás de la línea roja es solo para el personal. El personal puede descansar en la habitación (área verde). Se recomienda entrar a la habitación por turnos y seguir usando máscaras médicas a menos que estén comiendo o bebiendo ${ }^{20}$.

Según la OMS ${ }^{21}$ es recomendable una orientación sobre prevención y el control de infecciones durante la atención del paciente cuando se sospecha una infección por COVID-19. Además, es necesario el triaje previo a la atención para medir y registrar la temperatura de todos los miembros del personal y paciente como un procedimiento rutinario.

Los pacientes con fiebre serán derivados a los centros hospitalarios designados para la atención de pacientes con COVID-19 luego de su registro ${ }^{10}$. Y de ser el caso, donde el paciente haya estado en alguna región epidémica en los últimos 14 días, inmediatamente se sugiere la cuarentena durante al menos 14 días, criterios establecidos por la OMS ${ }^{20}$ (Tabla 1 ).

Las orientaciones sobre prevención a esta pandemia, deben mantenerse permanentemente en las salas de espera por parte del personal la cual además debe disminuir su capacidad en un $50 \%$ evitando las aglomeraciones y manteniendo la distancia entre personas de 1 a $2 \mathrm{~m}$, por lo tanto, es preferible que asistan solos a la consulta, excepto si acompañan a un nińo, o adultos mayores que requieran asistencia estrictamente de emergencia y cumpliendo con las medidas de protección adecuada. 


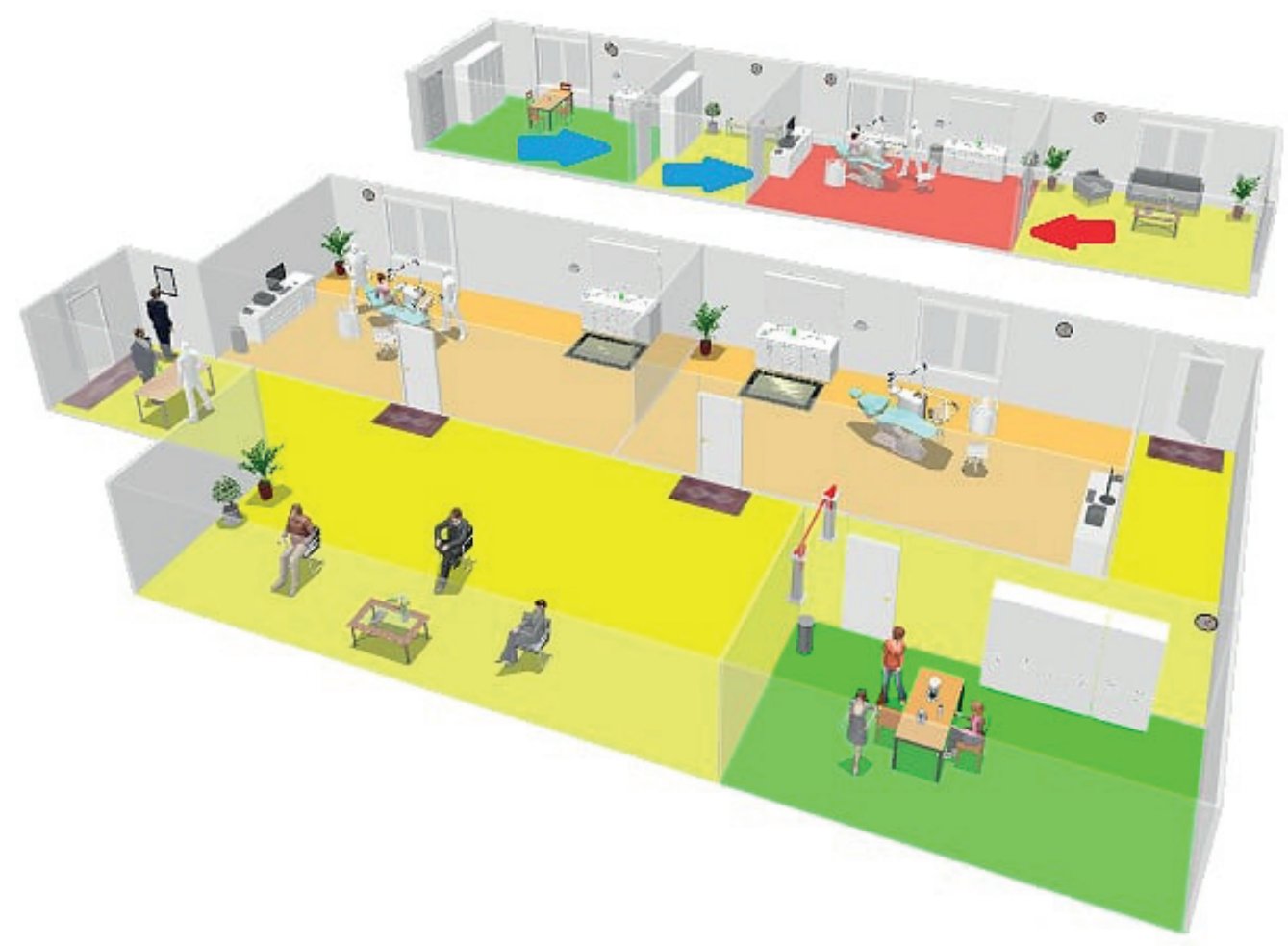

Figura 2. Divisiones del área odontológica para el tratamiento de pacientes ante la Pandemia de COVID-19: Zona amarilla: destinada para el Triaje y zona de espera o recepción. Zona Naranja: Clínica odontológica. Zona Roja: Clínica de aislamiento. Zona Verde: área de descanso solo para el personal. Se proporcionan entradas separadas para pacientes (flecha roja) y personal (flecha azul). Fuente: Elaborado a partir de Meng et al, 2020.

Tabla 1. Distribución de la anamnesis dirigida con preguntas realizadas durante el triaje odontológico

\begin{tabular}{|c|c|c|}
\hline \multirow{2}{*}{$\begin{array}{l}\text { Preguntas de control } \\
\text { Si / No }\end{array}$} & \multicolumn{2}{|c|}{ Conducta Clínica } \\
\hline & Temperatura $>37^{\circ} \mathrm{C}$ & Temperatura $<37^{\circ} \mathrm{C}$ \\
\hline $\begin{array}{l}\text { ¿Ha tenido fiebre en los últimos } 14 \text { días? } \\
\text { ¿Ha tenido problemas respiratorios en los } \\
\text { últimos } 14 \text { días } \\
\text { ¿Ha viajado a países con elevado número de } \\
\text { casos de COVID- } 19 \text { en los últimos } 14 \text { días? }\end{array}$ & $\begin{array}{l}\text { SI } \\
\text { A Cualquier Pregunta } \\
\text { Advertir al paciente sobre posible contagio } \\
\text { y remitir a una unidad de salud. }\end{array}$ & $\begin{array}{l}\text { SI } \\
\text { A Cualquier Pregunta } \\
\text { Paciente debe regresar en } 14 \text { días, a excep- } \\
\text { ción de presentar alguna urgencia dental. }\end{array}$ \\
\hline $\begin{array}{l}\text { ¿Ha estado en contacto con alguna persona } \\
\text { confirmada de COVID-19? } \\
\text { ¿Ha estado en contacto con personas que } \\
\text { presenten cuadro respiratorio agudo en los } \\
\text { últimos } 14 \text { días? }\end{array}$ & $\begin{array}{l}\text { NO } \\
\text { A Todas Las Preguntas } \\
\text { Paciente debe regresar en } 14 \text { días, a excep- } \\
\text { ción de presentar alguna urgencia dental. }\end{array}$ & $\begin{array}{l}\text { NO } \\
\text { A Todas Las Preguntas } \\
\text { Tratar al paciente con los cuidados y reco- } \\
\text { mendaciones }\end{array}$ \\
\hline
\end{tabular}

Fuente: Elaborado a partir de Tuñas IT de C. et al.

\section{Procedimientos odontológicos durante la pandemia COVID-19}

Antes de cualquier procedimiento odontológico se recomienda disminuir la flora microbiana de la cavidad bucal con un enjuague bucal antimicrobiano en el paciente ${ }^{21,22}$. Además, por recomendación de la OMS se debe evitar procedimientos que puedan causar tos por la emisión de gotas o caso contrario tomar las medidas de precaución necesarias; de igual manera, se debe evitar el uso de la jeringa triple o de tres vías durante el proceso de diagnóstico o tratamiento, el uso de dispositivos de alta succión para succionar la saliva a tiempo, puede reducir la generación de gotas y aerosoles ${ }^{14}$.
Antes del examen bucal, los pacientes pueden usar peróxido de hidrógeno al $0,5 \%$ o povidona yodada al $1 \%$, cloruro de cetilpiridinio al $0,05-0,10 \%$ o enjuagues bucales que reduzcan el número de microrganismos en gotas de saliva ${ }^{10,14,21 .}$ Los estudios in vitro han demostrado que los enjuagues de povidona yodada y el cloruro de cetilpiridinio pueden inhibir la actividad del coronavirus SARS$\mathrm{CoV}^{16,23,24}$. La clorhexidina al $0,12 \%$ no es eficaz ${ }^{10}$.

Debido a que la radiografía intraoral es el examen complementario más utilizado, se debe considerar que podría haber reflejos faríngeos que pueden causar náuseas, tos y vómito, por lo tanto, se puede considerar técnicas de imágenes extraorales ${ }^{25}$. 
En relación a los dispositivos y artículos de uso odontológico, se debe tratar de elegir los desechables y eliminarlos inmediatamente en un recipiente que contenga desinfectante de cloro de $1000 \mathrm{mg} / \mathrm{L}$ durante $30 \mathrm{mi}$ nutos. En caso de ser esterilizables, utilizar el vapor a presión (autoclave). Las telas deben sumergirse en un desinfectante que contenga cloro de $500 \mathrm{mg} / \mathrm{L}$ durante 30 minutos ${ }^{14}$.

Los diques de goma y los eyectores de saliva de alta succión pueden ayudar a minimizar el aerosol o las salpicaduras durante los procedimientos en la consulta odontológica.

A continuación, algunas recomendaciones tras la experiencia vivida en el hospital de Wuhan por la crisis causada por la aparición del COVID-19, en los casos que las patologías requieran asistencia ${ }^{20}$ :

- Se debe proceder al diagnóstico de COVID-19.

- Antes de la atención del paciente usar enjuague bucal antimicrobiano.

- A los pacientes se les debe evaluar signos y síntomas para determinar en que entorno clínico deben atenderse.

- Contactar con el paciente 1 a 2 días antes de cualquier sesión programada para corroborar si la visita en persona es necesaria o el problema puede resolverse sin una visita al consultorio.

- En el caso de pulpitis sintomática irreversible la exposición pulpar puede procederse con la remoción química-mecánica de la caries bajo aislamiento con dique de goma y un eyector de saliva de alta succión después de la anestesia local; posteriormente, se puede realizar la desvitalización pulpar para reducir el dolor.

- En el caso de necesitarse una extracción dental y sutura, se prefiere la sutura absorbible.

- En traumatismo facial de tejidos blandos, se debe realizar desbridamiento y sutura. Se recomienda enjuagar la herida lentamente y usar el eyector de saliva para evitar la pulverización.

- Los casos potencialmente mortales con lesiones complejas bucales y maxilofaciales deben ingresarse de inmediato a un hospital designado para pacientes con COVID-19 y se recomienda tomografía computarizada de tórax para apoyar el diagnóstico de la infección viral, en busca de resultados positivos por imágenes como recurso más rápido, aunque se debe sospechar y estar atentos de varios aspectos en la valoración del paciente como son la combinación de información epidemiológica, por ejemplo, el historial de viaje o residencia en la región afectada 14 días antes de la aparición de los síntomas. Las pruebas de laboratorio específicas para el diagnóstico del COVID-19 son otra alternativa como la prueba de reacción en cadena de la polimerasa con la transcriptasa inversa (RT-PCR), en muestras de tracto respiratorio. Cabe mencionar que un solo resultado negativo de la prueba de RT-PCR de pacientes sospechosos no excluye la infección. En conclusión, se debe estar atento de los síntomas de los pacientes sospechosos, antecedentes epidemiológicos y los resultados positivos de imágenes de tomografía computarizada de tórax en un primer momento.

- En el caso de dolor espontáneo debido a una fractura dental sin caries, se debe utilizar la pieza de mano de alta velocidad para la preparación cavitaria, en este caso se debe programar como el último paciente del día para disminuir el riesgo de infección nosocomial. Después del tratamiento, deben seguirse los procedimientos de limpieza y desinfección ambiental de rutina.

- Alternativamente, los pacientes podrían ser tratados en una habitación aislada y bien ventilada o habitaciones aisladas para casos sospechosos con COVID-19.

\section{Consideraciones para las emergencias odontológicas}

Con la finalidad de minimizar la transmisión del COVID-19 entre los pacientes y el equipo de profesionales en la consulta odontológica, así como proporcionar la mejor atención en las consultas se presenta las situaciones que son consideradas emergencias para la atención en el consultorio dental (Tabla 2); se presenta además el riesgo de trasmisión para el personal y paciente en la Tabla 3 basado en la ADA Interim Guidance for Management of Emergency and Urgent Dental Care ${ }^{26}$.

Tabla 2. Situaciones consideradas emergencias en pacientes sin síntomas respiratorios

\begin{tabular}{ll}
\hline & a. Dolor dental severo por inflamación pulpar. \\
& b. Pericoronitis o dolor en el tercer molar. \\
Emergencias sin & c. Osteítis postoperatoria quirúrgica, cambios de apósito seco. \\
síntomas & e. Absceso o infección bacteriana localizada que produce dolor e hinchazón localizados. \\
respiratorios & f. Trauma dental con avulsión / luxación. \\
& g. Cementación final de la corona / puente si la restauración temporal se pierde, se rompe o causa irritación gingival. \\
& h. Reemplazar la obturación temporal en endodoncia por acceso, en pacientes que experimentan dolor. \\
& i. Corte o adaptación de un alambre de ortodoncia o aparatos que perforan o ulceran la mucosa oral.
\end{tabular}

Fuente: Elaborado a partir de ADA $2020^{26}$ 
Tabla 3. Riesgo de trasmisión para personal de salud y paciente según lo expuesto en la tabla 1

\begin{tabular}{|c|c|c|}
\hline Riesgos & Recomendaciones & $\begin{array}{l}\text { Plan de tratamiento recomendado } \\
\text { para el paciente }\end{array}$ \\
\hline Bajo & a. No requiere cuarentena de 14 días & \multirow{3}{*}{$\begin{array}{l}\text { Remitir al paciente al departamento } \\
\text { de emergencias o al centro dental } \\
\text { que cumpla con los criterios estable- } \\
\text { cidos, de no ser factible su asistencia. }\end{array}$} \\
\hline Moderado & $\begin{array}{l}\text { b. Usar el juicio clínico y tomar todas las precauciones para evitar la transmisión. } \\
\text { c. Sugerir que el paciente sea examinado para Infección por COVID-19 después del } \\
\text { tratamiento dental } \\
\text { d. Si es positivo, debe poner en cuarentena por } 14 \text { días }\end{array}$ & \\
\hline Alto & $\begin{array}{l}\text { e. Utilice el juicio clínico y tome todas las precauciones. para prevenir la transmisión. } \\
\text { f. Si se implementa el tratamiento, exija que el paciente se realice la prueba para } \\
\text { detectar la infección por COVID-19 inmediatamente después del tratamiento; si es } \\
\text { positivo cuarentena durante } 14 \text { días todos los profesionales }\end{array}$ & \\
\hline
\end{tabular}

Fuente: Elaborado a partir de ADA $2020^{26}$

Determinar el riesgo de contagio del paciente juega un papel importante en la seguridad de la atención odontológica ${ }^{27}$. Las urgencias dentales deben ser priorizadas tomando todas las consideraciones necesarias ${ }^{28}$, incluidos los protocolos de atención determinados en el área médica que pueden servir para un correcto triaje del paciente y así minimizar los riesgos en la consulta odontológica ${ }^{29,30}$.

\section{Conclusiones}

Durante el control de la pandemia del COVID-19, la atención odontológica de urgencia debe priorizarse a los tratamientos de rutina, es imprescindible evaluar la condición clínica del paciente para determinar la presencia de cualquier síntoma relacionado con la infección viral y trabajar acorde al nivel de riesgo del mismo. Son muchos los desafíos que aún quedan por enfrentar para regresar a los tratamientos odontológicos de manera convencional, por consiguiente, los profesionales deben cumplir estrictamente las normas de bioseguridad, ética y actualización continua para responder apropiadamente a este nuevo reto.

\section{Referencias bibliográficas}

1. Li ZY, Meng LY. [The prevention and control of a new coronavirus infection in department of stomatology]. Zhonghua Kou Qiang Yi Xue Za Zhi. 2020;55(0):E001.

2. Singhal T. A Review of Coronavirus Disease-2019 (COVID-19). Indian J Pediatric. 2020;87(4):281-6.

3. Wang D, Hu B, Hu C, Zhu F, Liu X, Zhang J, et al. Clinical Characteristics of 138 Hospitalized Patients With 2019 Novel Coronavirus-Infected Pneumonia in Wuhan, China. JAMA. 2020;323(11):1061-9.

4. Peng X, Xu X, Li Y, Cheng L, Zhou X, Ren B. Transmission routes of $2019-\mathrm{nCoV}$ and controls in dental practice. Int J Oral Sci. 2020;12(1):9.

5. Kampf G, Todt D, Pfaender S, Steinmann E. Persistence of coronaviruses on inanimate surfaces and their inactivation with biocidal agents. J Hosp Infect. 2020;104(3):246-51.

6. Chen N, Zhou M, Dong X, Qu J, Gong F, Han Y, et al. Epidemiological and clinical characteristics of 99 cases of 2019 novel coronavirus pneumonia in Wuhan, China: a descriptive study. Lancet. 2020;395(10223):507-13.
7. Farooq I, Ali S. COVID-19 outbreak and its monetary implications for dental practices, hospitals and healthcare workers. Postgrad Med J. 2020 DOI: 10.1136 / postgradmedj-2020-137781

8. Jordan RE, Adab P, Cheng KK. Covid-19: Risk Factors for Severe Disease and Death. BMJ. 2020;368. DOI: 10.1136/bmj.m1198.

9. Zhou M, Zhang X, Qu J. Coronavirus disease 2019 (COVID-19): a clinical update. Front Med. 2020. DOI: 10.1007/s11684-020-0767-8.

10. Tuńas IT de C, Silva ET da, Santiago SBS, Maia KD, Silva-Júnior GO. Doença pelo Coronavírus 2019 (COVID-19): Uma abordagem preventiva para Odontologia. Rev Bras Odontol. 2020;77:e1766. DOI: http://dx.doi. org/10.18363/rbo.v77.2020.e1766.

11. Sabino-Silva R, Jardim ACG, Siqueira WL. Coronavirus COVID-19 impacts to dentistry and potential salivary diagnosis. Clin Oral Investig. 2020;;24(4):1619-21.

12. To KK-W, Tsang OT-Y, Yip CC-Y, Chan K-H, Wu T-C, Chan JM-C, et al. Consistent Detection of 2019 Novel Coronavirus in Saliva. Clin Infect Dis. 2020 DOI: $10.1093 /$ cid / ciaa149

13. Doerrbecker J, Friesland M, Ciesek S, Erichsen TJ, Mateu-Gelabert P, Steinmann J, et al. Inactivation and survival of hepatitis $C$ virus on inanimate surfaces. J Infect Dis. 2011;204(12):1830-8.

14. Center For Disease Control and Prevention. Guidelines For Infection Control in Dental Health-Care Settings-2003. MMWR. 2003;52(RR-17):1-68.

15. Samaranayake LP, Peiris M. Severe acute respiratory syndrome and dentistry: A retrospective view. J Am Dent Assoc. 2004;135(9):1292-302.

16. Kariwa H, Fujii N, Takashima I. Inactivation of SARS Coronavirus by Means of Povidone-Iodine, Physical Conditions and Chemical Reagents. Dermatology. 2006;212(Suppl 1):119-23.

17. Bartoszko JJ, Farooqi MAM, Alhazzani W, Loeb M. Medical Masks vs N95 Respirators for Preventing COVID-19 in Health Care Workers A Systematic Review and Meta-Analysis of Randomized Trials. Influenza Other Respi Viruses. 2020 DOI: 10.1111/irv. 12745.

18. Fisher EM, Shaffer RE. Considerations for Recommending Extended Use and Limited Reuse of Filtering Facepiece Respirators in Healthcare Settings. J 
Occup Environ Hyg. 2014; 11(8):D115-28. DOI 10.1080/15459624.2014.902954.

19. Dave M, Seoudi N, Coulthard P. Urgent dental care for patients during the COVID-19 pandemic. Lancet. 2020;395(10232):1257. DOI: 10.1016/S01406736(20)30806-0

20. Meng L, Hua F, Bian Z. Coronavirus Disease 2019 (COVID-19): Emerging and Future Challenges for Dental and Oral Medicine. J Dent Res. 2020:002203452091424. DOI: $10.1177 / 0022034520914246$.

21. World Health Organization. Q\&A on coronaviruses (COVID-19) [consultado el 26 de febrero 2020]. Accesible en: https://www.who.int/news-room/q-a-detail/ q-a-coronaviruses.

22. Marui VC, Souto MLS, Rovai ES, Romito GA, Chambrone L, Pannuti CM. Efficacy of preprocedural mouthrinses in the reduction of microorganisms in aerosol: A Systematic Review. J Am Dent Assoc. 2019;150(12):1015-26.

23. Eggers M, Eickmann M, Zorn J. Rapid and Effective Virucidal Activity of Povidone-Iodine Products Against Middle East Respiratory Syndrome Coronavirus (MERS-CoV) and Modified Vaccinia Virus Ankara (MVA). Infect Dis Ther. 2015;4(4):491-501.

24. Shen L, Niu J, Wang C, Huang B, Wang W, Zhu N, et al. High-Throughput Screening and Identification of Potent Broad-Spectrum Inhibitors of Coronaviruses. J Virol. 2019;93(12):e00023-19. DOI: 10.1128/JVI.00023-19.
25. Vandenberghe B, Jacobs R, Bosmans H. Modern dental imaging: a review of the current technology and clinical applications in dental practice. Eur Radiol. 2010;20(11):2637-55.

26. American Dental Association. ADA Interim Guidance for Management of Emergency and Urgent Dental Care. [Consultado el 7 de abril 2020]. Accesible en: https:// www.ada.org/ /media/CPS/Files/COVID/ADA_Int_ Guidance_Mgmt_Emerg-Urg_Dental_COVID19.pdf.

27. Xu H, Zhong L, Deng J, Peng J, Dan H, Zeng X, et al. High expression of ACE2 receptor of 2019-nCoV on the epithelial cells of oral mucosa. Int J Oral Sci. 2020;12(1):8. DOI: 10.1038/s41368-020-0074-x.

28. Sepúlveda VC, Secchi AA, Donoso-Hofer F. Urgency Dental Care Considerations in the Context of Coronavirus COVID-19 (SARS-CoV-2). Int J Odontostomat. 2020;14(3):279-84.

29. Sociedad Mexicana de Medicina de Emergencias, A.C. Protocolo de atención para COVID-19 (SARS-CoV-2) de la Sociedad Mexicana de Medicina de Emergencias. [Consultado el 18 de abril 2020]. Accesible en: https:// www.flasog.org/static/COVID-19/GuiaCOVID19SMME.pdf

30. Suarez SS, Campuzano R, Vidale MD, Garrido CE, Gimenez MT. Recomendaciones para prevención y control de infecciones por SARS-CoV-2 en odontología. Odontología. 2020;22(2):5-32. 